\title{
DESIGN DEVELOPMENT AND CHARACTERIZATION SUPER HYDROPHOBIC SURFACE COATING ON WOOD MATERIALS
}

\author{
Hazim Moria \\ Department of Mechanical Engineering Technology, Yanbu Industrial College, \\ Yanbu Al-Sinaiyah 41912, Kingdom of Saudi Arabia
}

\begin{abstract}
Reliable PDMS and aluminum NPS coating have been developed to protect the wood from deterioration and other water-absorbing materials in humid conditions. Thus, alumina that readily available was utilized to make a harsh surface, which afterward combined chemically with PDMS to develop the hydrophobic characteristics. A few substitute layers of PDMS together with alumina particles were established to ensure hydrophobic properties, and the water impact and emery paper tests were investigated. The glass substrates and other hydrophilic materials were used to apply the coating to limit its water absorption. The coated wood that developed super-hydrophobic properties was examined by difference and change in contact angle by analyzing the level of water absorption in covered and uncovered wood samples.
\end{abstract}

Key words: Durable, Hydrophilic, PDMS, Wood protection, Nanoparticles, Superhydrophobic, WCA

Cite this Article: Hazim Moria, Design Development and Characterization Super Hydrophobic Surface Coating on Wood Materials, International Journal of Advanced Research in Engineering and Technology, 10(5), 2019, pp 73-80.

$\mathrm{http}: / /$ iaeme.com/Home/issue/IJARET?Volume $=10 \&$ Issue $=5$

\section{INTRODUCTION}

Wood is one of the organic materials used in the production of several products like wooden edges, frames, etc. Along with the fact that wood is easily available and cost-effective, it has great properties such as lightweight, rigid, accessible in large quantities and also cheap. All these things play a vital role in making wood raw material as reported by S.L. Bardage (2017). Moreover, cracks and shrinkage caused by absorbance of water lead to volume degradation in wood. In order to limit this hydrophilic nature, various studies and procedures have been evolved. More hydrophilic materials such as ceramics are having the same problem as notified by Lars A. Berglund (2018). Hongli Zhu, Wei Luo (2016) investigated that wood contains hemicelluloses, cellulose, and lignin. The performance of Wood is affected by its hygroscopic property. Hydrophilic molecules are documented in Chao Jia (2017) as it has a porous structure and absorbs water, and can provide a way to run fluid. This phenomenon of 
microorganism's activity increases in the humid environment, and it also reduces the stability of wood as indicated by Micheal D. Ulyshen (2014). Normally, the content of moisture found in wood lies between $8 \%$ to $25 \%$ in terms of weight, which relatively depends on the humidity present in air. The strengthen properties of wood are advanced as the wood is dried as outlined by Simon Roucheir (2017).

Wentao Gan (2015) addressed that by avoiding the interaction of water with wood materials, the dilapidation of its structure can be avoided and possible by applying the hydrophobic layers on these surfaces. Less surface energy, in combination with multi roughness of scale, is used to prepare the hydrophobic layer. These layers have applications in numerous fields such as separating oil-water industry. Ben Wang (2014) stated that surface properties profoundly affect its performance in its applications like replication of surface, molding surface, microfluidic gadgets. Some experiments have been done before to check the interaction of water with wood-like 154 contact angle of water with hydrophobic surface and formed by applying silica nanoparticles with vinyltriethoxysilane as documented by Yiagiang $\mathrm{Wu}(2016)$.

Another example is the hydrophobic coating of zinc oxide, and carnauba wax is formed to prevent from UV radiations and water. The hierarchical structure of titania was formed on wood's surface by the addition of perfluorodecyltriethoxysilane to form a water-repellant surface with angle of WCA greater than 140 as reported by Jitha S. Jayana (2019). Moreover, a coating of composite of silica also formed by using a process known as hydrothermal process for wood's protection. It is the mutual effect of nano-size PDMS and alumina particles in super-hydrophobic layers, as stated by Chunyan Cao (2016).

This experiment can lead to wonders in the wood industry and will tackle the issue that arises due to water absorption by materials like poor mechanical properties, degradation of wood due to microorganisms, shrinking or swelling of wood due to diffusion and osmosis thus limiting its applications. In this study, an investigation has been executed to make a hydrophobic coating for the protection of materials are hydrophilic. By applying the superhydrophobic coating and limiting the interaction of water and substrate, this study will be able to resolve all the problems stated above as reported by John T. Simpson (2015).

\section{MATERIALS AND METHODS}

\subsection{Materials}

The first particle size analysis for alumina suspension was carried out with the help of the laser particle analyzer. Ball friction of alumina with ethanol performed for an hour in order to reduce the size of alumina, and then laser particle analyzer reports again generated. In this study, we did ball milling of alumina for one more to get the desired nanoparticles then dried it for 24 hours in drying furnace to use if for making a suspension.

\subsection{Methods}

After ball milling, the solution of alumina made of $0.5 \mathrm{wt} \%$ of $\mathrm{Al}_{2} \mathrm{O}_{3}-\mathrm{NPS}$ and poured in a beaker with $100 \mathrm{ml}$ ethanol mixed. Sonication of this suspension was done for $30 \mathrm{~min}$ in Ultrasonic cleaner for mixing them properly as documented by I.M.Mahbubula (2017). To prepare PDMS solution, 1.0\% PDMS solution was poured in a beaker and stirred in $50 \mathrm{ml} n$ hexane and curing agent weighed $0.1 \mathrm{~g}$ and poured in another beaker and gathered in another $50 \mathrm{ml} \mathrm{n}$-hexane. After stirring and mixing for 10 minutes, both of the solutions we prepared were mixed, and 10 minutes more stirring was done to prepare the coating as reported by Kuruma Malkappa (2015). 
The coating was applied by dip-coating method. Firstly, glass slides were dipped in Alumina nanoparticles solution for 30 seconds and then put in the oven with the help of tong at $50{ }^{\circ} \mathrm{C}$ for 5 minutes. After that, these alumina coated glass slides dipped in PDMS solution for 30 seconds, and a thin layer is formed to be dried at same temperature in 20 minutes. This complete coating cycle contains a layer of alumina particles coating which is followed by a coating of PDMS. Many samples of this complete coating taken three cycles and many samples of this complete coating taken three cycles. These samples were then given for characterization to check the coating's durability as reported R. Seighir (2017).

\section{EXPERIMENTAL WORK}

These samples were then given for characterization to examine the coating's durability as reported by $\mathrm{Mu}$ Rui (2017). The surface contact angles of the super-hydrophobic material should be above $150^{\circ}$, and the contact angle hysteresis should be as low as reported by Duong v. Ta (2015). Due to this reason, WCA was measured to determine the hydrophobicity of the coating, which synthesized as reported by Kuruma Malkappa (2015). The WCA test is displaying in Figure 1 to 4.

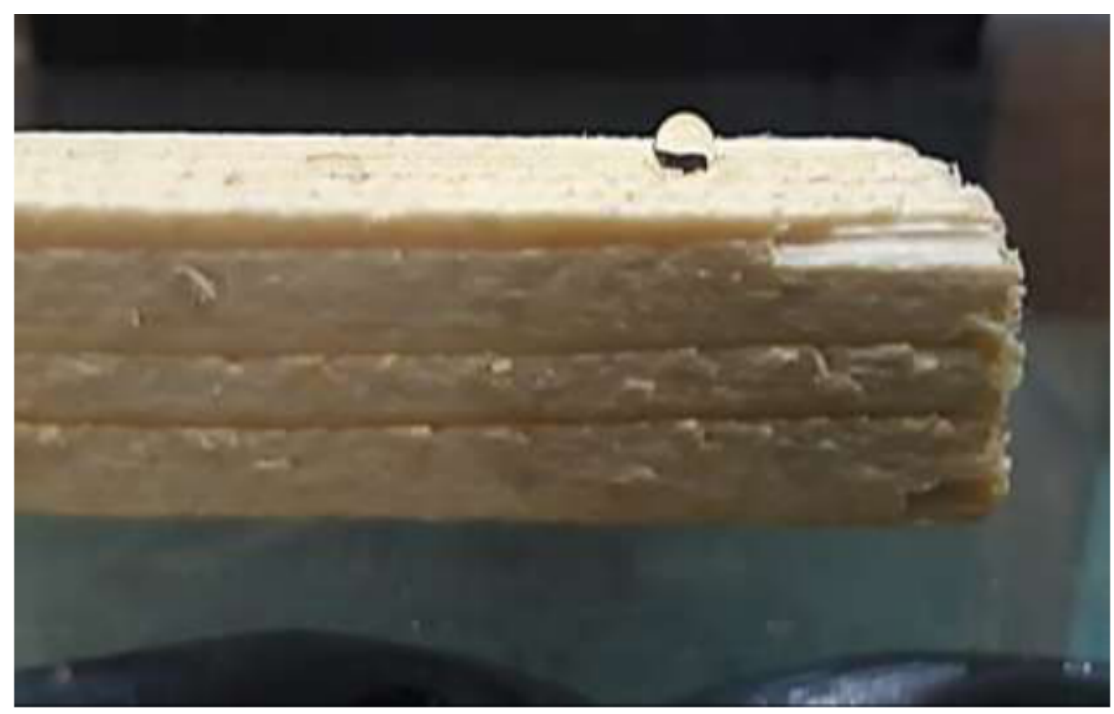

Figure 1. Super hydrophobic wood

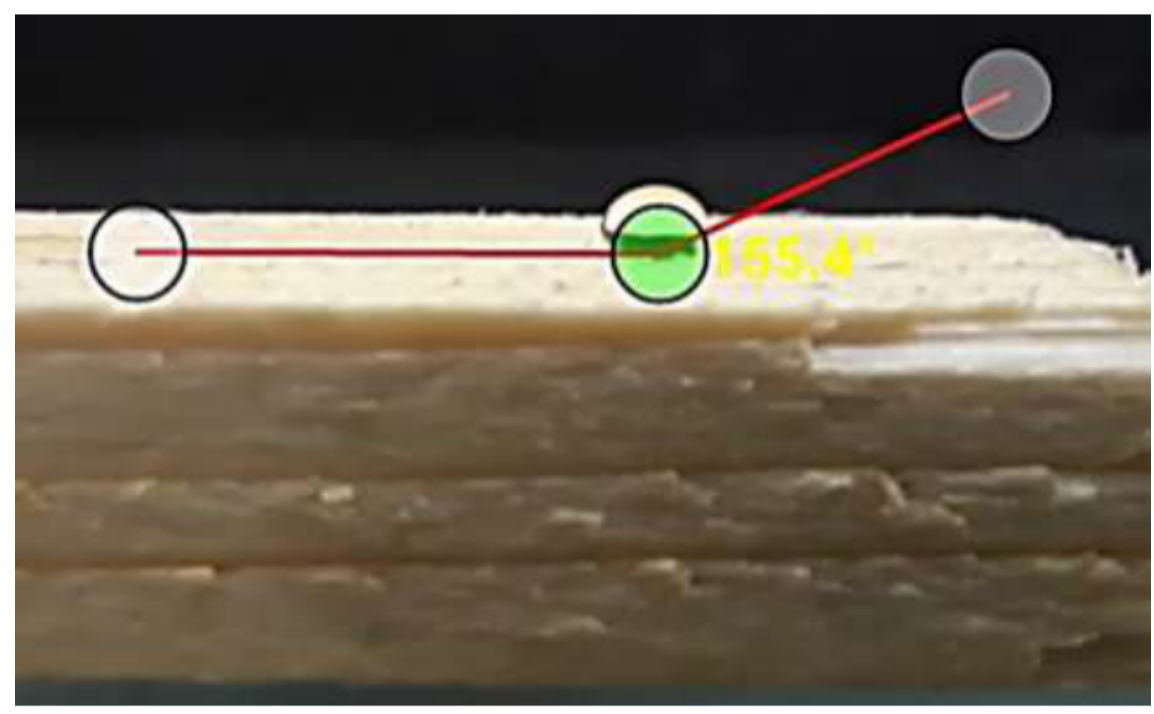

Figure 2. First reading of water contact angle 


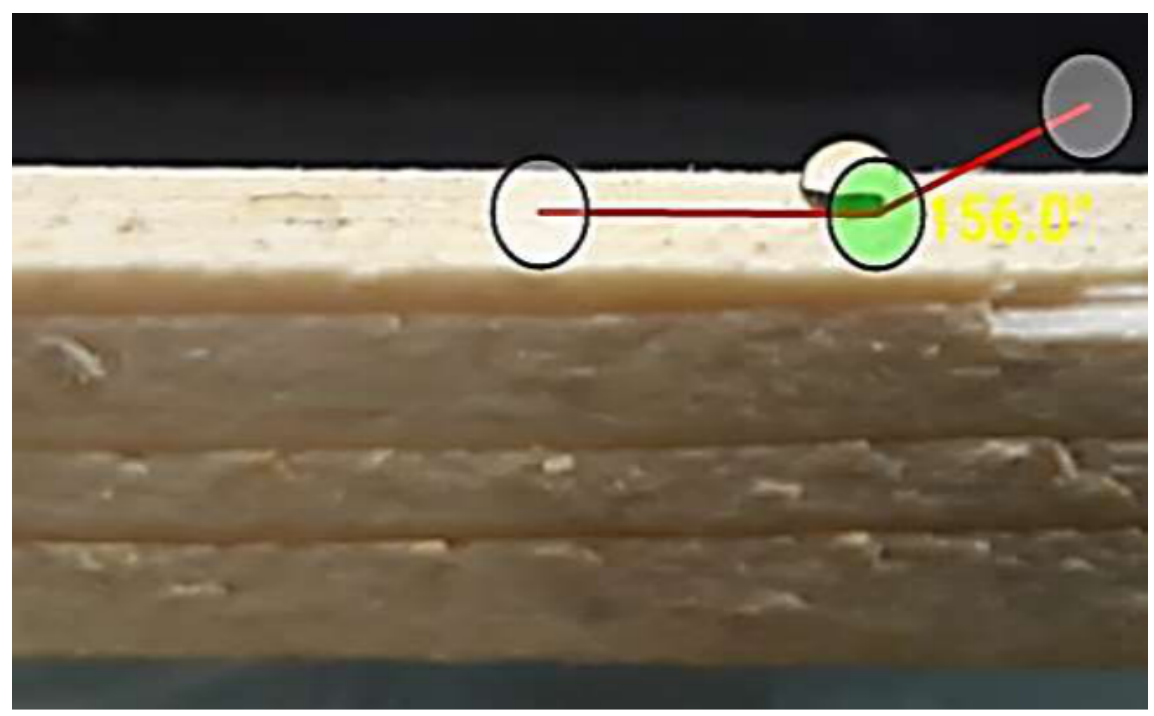

Figure 3. Second reading of water contact angle

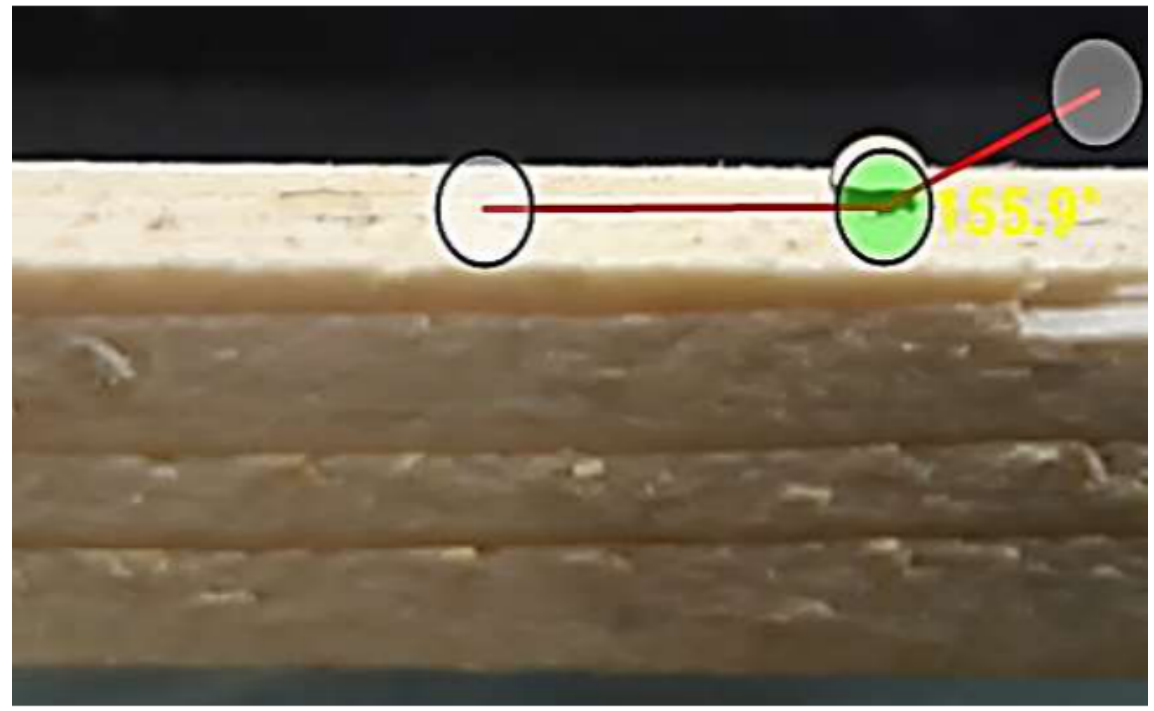

Figure 4. Third reading of water contact angle

Water absorption test is another way to check hydrophobicity of material as reported by Liu X1 (2015). When the superhydrophobic sample is dipped into the water for a particular given period, it repels water as reported by Athanasios Milionis (2015). Whereas the sample with no hydrophobic coating absorbs water which results in an increase in weight of the sample with no hydrophobic coating (see Figure 5). 


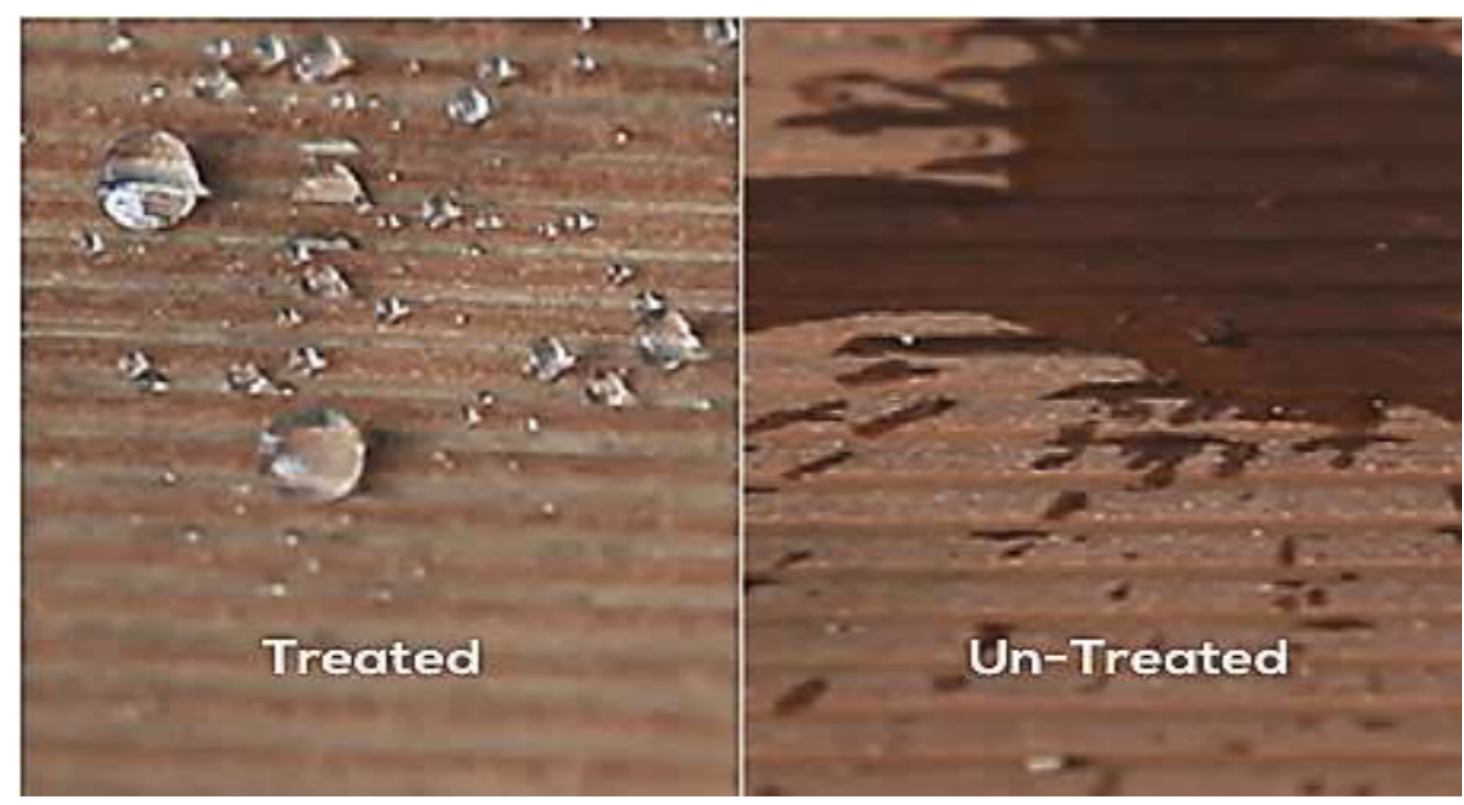

Figure 5. Hydrophobic wood, (a) Treated and (b) Un-Treated.

The test was carried out by using a weight balance. First, the weight of both samples (coated and non-coated) was measured. Then the samples were dipped in the beaker for about 5 minutes. After that, the weight of both samples measured again, and the results were calculated.

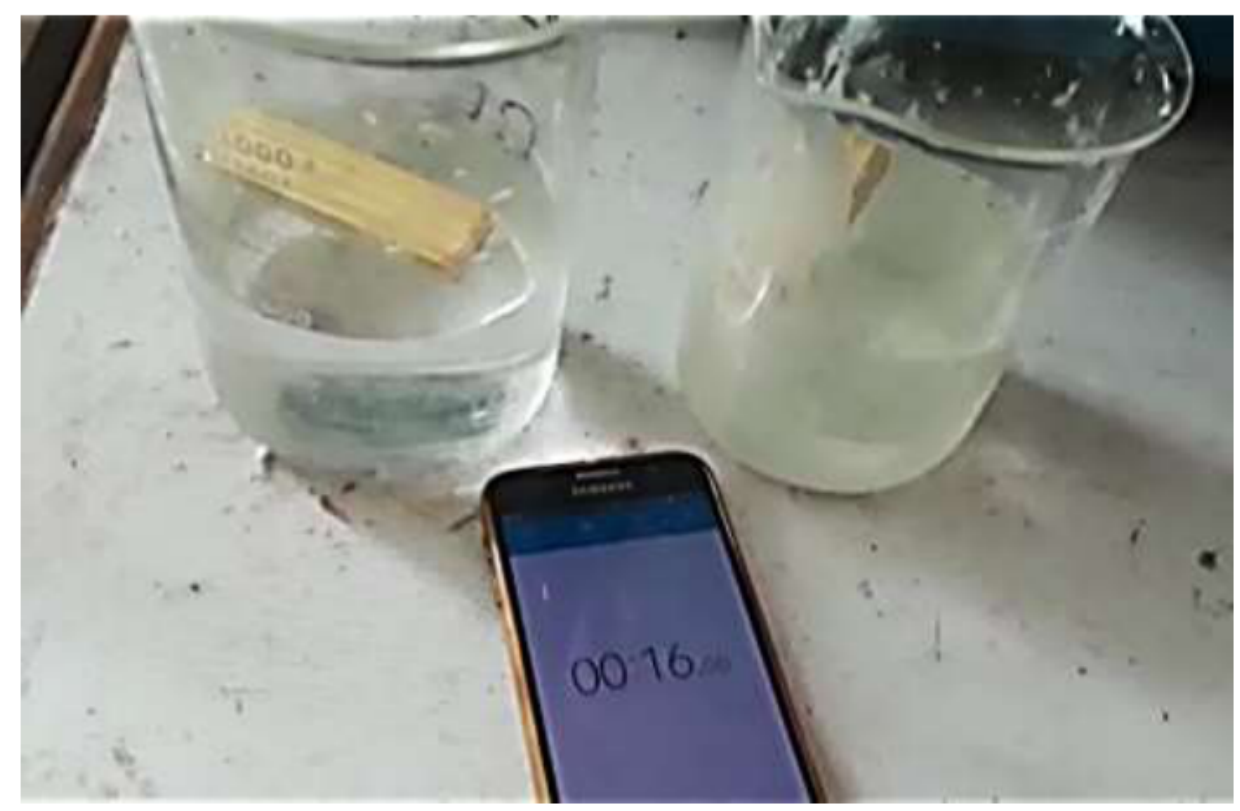

Figure 6. Initial image of water absorption.

The entire procedures were carried out as follows:

1. Weight the samples before water absorption test.

2. Weight samples before the water absorption test was found to be:

a. Uncoated sample: $8.44 \mathrm{~g}$.

b. Coated sample: $9.40 \mathrm{~g}$.

3. Weight the samples after water absorption test.

4. Weight, the samples before the water absorption test, was found to be: 
a. Uncoated sample: $9.98 \mathrm{~g}$.

b. Coated sample: $15.72 \mathrm{~g}$.

\section{RESULTS AND DISCUSSIONS}

Table 1 shows the experimental results obtained from the WCA tests. The required water contact angle for a surface to become super-hydrophobic is supposed to be above $150^{\circ}$. The results provided affirm the super-hydrophobicity of PDMS-Alumina coating synthesized during the experiments. The acquired findings from Water Absorption test are given in Table 2. The weight increment of uncoated sample was found to $7.28 \mathrm{~g}$ in 5 minutes whereas the weight increment of the coated sample was found to be 0.58 which indicates the effect of super-hydrophobicity PDMS-Alumina coating.

Table 1 WCA measurements

\begin{tabular}{cc}
\hline NO & Reading \\
\hline 1 & $155.4^{\circ}$ \\
2 & $155.9^{\circ}$ \\
3 & $156.0^{\circ}$ \\
Mean & $155.7^{\circ}$ \\
\hline
\end{tabular}

Table 2 Water absorption test measurements

\begin{tabular}{cc}
\hline NO & Reading \\
\hline \multicolumn{2}{c}{ Coated Sample } \\
Weight before the test & 9.40 \\
Weight after the test (g) & 9.98 \\
Weight difference (g) & 0.58 \\
Un-coated Sample \\
Weight before the test \\
Weight after the test (g) \\
Weight difference (g) \\
\hline
\end{tabular}

\section{CONCLUSIONS}

A super-hydrophobic coating of PDMS and NPS of alumina was made to protect the wood from deterioration and other water-absorbing materials in moist situations. Glass substrates and other hydrophilic materials were used for application of coating to limit their ability to absorb water. Moreover, the experimental results revealed that the coating was successfully developed.

\section{ACKNOWLEDAGMENTS}

The author is thankful to the Assistant Professor Dr. Shahid Hussain Abro, Materials and Metallurgical Engineering Department, NED University of Engineering and Technology for his advice and suggestions this research. 
Design Development and Characterization Super Hydrophobic Surface Coating on Wood Materials

\section{REFERENCES}

[1] Milionis, A., Dang, K., Prato, M., Loth, E. and Bayer, I.S. Liquid repellent nanocomposites obtained from one-step water-based spray. Journal of Materials Chemistry A, 3(24), 2015, pp.12880-12889.

[2] Wang, B., Liang, W., Guo, Z. and Liu, W. Biomimetic super-lyophobic and superlyophilic materials applied for oil/water separation: a new strategy beyond nature. Chemical Society Reviews, 44(1), 2015, pp.336-361.

[3] Jia, C., Li, Y., Yang, Z., Chen, G., Yao, Y., Jiang, F., Kuang, Y., Pastel, G., Xie, H., Yang, B. and Das, S. Rich mesostructures derived from natural woods for solar steam generation. Joule, 1(3), 2017, pp.588-599.

[4] Cao, C., Ge, M., Huang, J., Li, S., Deng, S., Zhang, S., Chen, Z., Zhang, K., Al-Deyab, S.S. and Lai, Y. Robust fluorine-free superhydrophobic PDMS-ormosil@ fabrics for highly effective self-cleaning and efficient oil-water separation. Journal of Materials Chemistry A, 4(31), 2016, pp.12179-12187.

[5] Ta, D.V., Dunn, A., Wasley, T.J., Kay, R.W., Stringer, J., Smith, P.J., Connaughton, C. and Shephard, J.D. Nanosecond laser textured superhydrophobic metallic surfaces and their chemical sensing applications. Applied Surface Science, 357, 2015, pp.248-254.

[6] Zhu, H., Luo, W., Ciesielski, P.N., Fang, Z., Zhu, J.Y., Henriksson, G., Himmel, M.E. and $\mathrm{Hu}, \mathrm{L}$. Wood-derived materials for green electronics, biological devices, and energy applications. Chemical Reviews, 116(16), 2016, pp.9305-9374.

[7] Mahbubul, I.M., Elcioglu, E.B., Saidur, R. and Amalina, M.A. Optimization of ultrasonication period for better dispersion and stability of $\mathrm{TiO}_{2}$-water nanofluid. Ultrasonics sonochemistry, 37, 2017, pp.360-367.

[8] Jayan, J.S., Jayadev, D., Pillai, Z.S., Joseph, K. and Saritha, A. The stability of the superhydrophobic surfaces. In Superhydrophobic Polymer Coatings, 2019, pp. 123-159. Elsevier.

[9] Simpson, J.T., Hunter, S.R. and Aytug, T. Superhydrophobic materials and coatings: a review. Reports on Progress in Physics, 78(8), 2015, p.086501.

[10] Ahmad, K. and Pan, W. Microstructure-toughening relation in alumina based multiwall carbon nanotube ceramic composites. Journal of the European Ceramic Society, 35(2), 2015, pp.663-671.

[11] Malkappa, K. and Jana, T. Hydrophobic, water-dispersible polyurethane: role of polybutadiene diol structure. Industrial \& Engineering Chemistry Research, 54(30), 2015, pp.7423-7435.

[12] Berglund, L.A. and Burgert, I. Bioinspired wood nanotechnology for functional materials. Advanced Materials, 30(19), 2018, p.1704285.

[13] Liu, X., Yi, Q., Han, Y., Liang, Z., Shen, C., Zhou, Z., Sun, J.L., Li, Y., Du, W. and Cao, R. A robust microfluidic device for the synthesis and crystal growth of organometallic polymers with highly organized structures. Angewandte Chemie International Edition, 54(6), 2015, pp.1846-1850.

[14] Ulyshen, M.D. Wood decomposition as influenced by invertebrates. Biological Reviews, 91(1), 2016, pp.70-85.

[15] MU, R. and DENG, A. Study of Preparation and Performance of Polymer Emulsion Filmforming Material for Fingerprint-resistant Coating. Plating \& Finishing, 7, 2017, p.2.

[16] Seghir, R. and Arscott, S. Extended PDMS stiffness range for flexible systems. Sensors and Actuators A: Physical, 230, 2015, pp.33-39. 
[17] MU, R. and DENG, A. Study of Preparation and Performance of Polymer Emulsion Filmforming Material for Fingerprint-resistant Coating. Plating \& Finishing, 7, 2017, p.2.

[18] Bardage, S.L. Performance of buildings. In Performance of Bio-based Building Materials, 2017, pp. 335-383. Woodhead Publishing.

[19] Rouchier, S., Busser, T., Pailha, M., Piot, A. and Woloszyn, M. Hygric characterization of wood fiber insulation under uncertainty with dynamic measurements and Markov Chain Monte-Carlo algorithm. Building and Environment, 114, 2017, pp.129-139.

[20] Gan, W., Gao, L., Sun, Q., Jin, C., Lu, Y. and Li, J. Multifunctional wood materials with magnetic, superhydrophobic and anti-ultraviolet properties. Applied Surface Science, 332, 2015, pp.565-572.

[21] Wu, Y., Jia, S., Qing, Y., Luo, S. and Liu, M. A versatile and efficient method to fabricate durable superhydrophobic surfaces on wood, lignocellulosic fiber, glass, and metal substrates. Journal of Materials Chemistry A, 4(37), 2016, pp.14111-14121.

[22] Dr. P. Sugunalakshmi and A. Rathina Maheswari. Consumer Durable Industry in India Present Trend, Challenges and Future Prospects. International Journal of Management, 7(2), 2016, pp. 449-453.

[23] Ahmed Thabet, Experimental Investigation on Thermal Electric and Dielectric Characterization for Polypropylene Nanocomposites Using Cost-Fewer Nanoparticles, International Journal of Electrical Engineering and Technology (IJEET), Volume 4, Issue 2, March - April (2013), pp. 01-12.

[24] Jayakumar, N., Dr. Mohanamurugan, S., Dr. Rajavel, R. and Srinivasan, V. Morphological Characterisation of Poly Methyl Methacrylate for Surface Coating of Metals. International Journal of Mechanical Engineering and Technology, 6(8), 2015, pp. 139-143.

[25] Sunil Takalapally, Sumith Kumar, Sri Harsha Pusuluri and Manasa Palle, A Critical Review on Surface Coatings for Engineering Materials. International Journal of Mechanical Engineering and Technology, 7(5), 2016, pp. 80-85. 